\title{
Polycyclic Aromatic Hydrocarbons (PAHs) Content in Cattle Hides and Meat Singed with Scrap Rubber Tyres
}

\author{
*1NNAJI, JC; MADU, ES; CHUKWUEMEKA-OKORIE, HO \\ Department of Chemistry, Michael Okpara University of Agriculture, Umudike, P. M. B. 7267, Umuahia, Abia State, Nigeria. \\ "corresponding author: Phone: +2348067711846; dozis03@yahoo.com
}

\begin{abstract}
Scrap rubber tyre is used as fuel for singeing animal carcasses in third world countries despite the fact that it can impart hazardous substances like polycyclic aromatic hydrocarbons (PAHs) on meat. The PAH contents of cattle hide and meat samples singed with flame produced by scrap car tyre in abattoirs located in Umuahia, Aba, Okigwe and Mbaise, South-Eastern Nigeria, were evaluated with Gas chromatography fitted with flame ionization detector (GC-FID). The target analytes were the sixteen non-alkylated priority PAHs which were determined in the samples through ultrasonic extraction, sample clean up and GC-FID analysis. The results revealed that mean concentrations of the carcinogenic PAH, benzo(a)pyrene in the consumer ready singed and washed samples from Aba were lower than EU limit of $2 \mu \mathrm{g} / \mathrm{kg}$. For samples collected from Umuahia, mean benzo(a)pyrene concentrations were higher in the consumer ready singed washed hide and meat samples compared to the EU limit. Mean benzo(a)pyrene concentrations in the singed washed samples from Okigwe and Mbaise were also lower than the EU limits. The results indicate that the use of rubber tyres for singeing cattle hides and meat can deposit dangerous levels of PAHs which puts consumers of such products at the risk of health hazards like cancer. It is recommended that government at all levels should enact and strictly enforce laws banning the use of scrap rubber tyres for processing food. $\bigcirc \mathrm{JASEM}$

https://dx.doi.org/10.4314/jasem.v21i6.19
\end{abstract}

Keywords: Cattle hide, meat, tyre, singeing, hydrocarbons

Large quantities of hazardous substances are discharged into the environment daily and many of these substances are toxic to humans, other animals and plants especially when their concentrations are above maximum permissible levels, MPL (Adam et al., 2013). Hazardous substances are those substances which are harmful and pose health risks to biota and the environment. Humans live and work among a wide variety of hazardous substances; in industrial production, storage and use; and in active and abandoned hazardous waste sites. Hazardous substances are also found in many consumer products (foods) and services that are used every day. When these substances enter the environment, they contaminate land, water, food and the air with potentially disastrous effects. Although some hazardous substances may occur naturally through some natural phenomenon (like earthquake and volcanic eruption), man and his activities still remain the major sources of these hazardous substances.

Hazardous substances are deposited on meat during processing thereby posing health risks to the consumers of the meat (Alonge, 1988). The type of hazardous substances deposited on the meat depends on the substance used as fuel for meat processing. Traditionally, firewood has been the main source of fuel for singeing butchered animals but in recent times the high cost of firewood has resulted in the use of scrap car tyres as an alternative fuel for singeing and other forms of meat processing in some third world countries (Obiri-Danso et al., 2008). Scrap tyre, according to the local butchers are cheaper and produces more flame with less heat hence, it is able to selectively burn off the fur from the animal easily and does not crack the hides (Obiri-Danso et al., 2008).
However, the use of tyres as fuel for singeing is reported to impart hazardous substances in high concentrations and some toxic heavy metals which could diffuse into the meat, thus rendering the meat unsafe for consumption (Okiel et al., 2000).

Numerous factors related to singeing, smoking and roasting processes are neglected in the developing world and the deposition of hazardous substances on the products of meat processing is not given adequate attention (Garcia-Falcon and Simal-Gandara, 2005). Singeing of slaughtered cattle hides with scrap tyres as fuel source could introduces high levels of polycyclic aromatic hydrocarbons (PAHs) in the hide and meat due to high temperatures, oxidation, and incomplete combustion of organic compounds contained in the tyre (Hamparsun and Hilal, 2010). The deposition of PAHs on cow hide and meat samples singed with scrap rubber tyres collected from the major abattoirs in Abia and Imo States of SouthEastern Nigeria - Umuahia, Aba, Okigwe and Mbaise - is studied in this work.

\section{MATERIALS AND METHODS}

Study Areas: The study areas were Aba, Umuahia (both in Abia State), Okigwe and Mbaise (both in Imo State). The abattoirs are located in Forest Valley (Umuahia), across railway to Ama-Ogbonna junction called Over-rail by cemetery road axis (Aba), forest side behind abattoir (Okigwe) and Afor-Ogbe (Mbaise).

Sample Collection and Preparation: Cattle hide samples with meat (200 g each) were collected from the hip area of slaughtered cattle and used for this study. They comprised of 36 hide and 36 meat 
samples. 12 hide and 12 meat sample were collected from slaughtered cow carcasses before singeing while 12 hide and 12 meat samples were collected after singeing with scrap automobile rubber tyres before washing. A further 12 hide and 12 meat samples were collected after the singed material were washed with water in abattoirs located in Aba, Umuahia, Okigwe and Mbaise. Three unsigned hide (UH), three unsigned meat (UM); three singed unwashed hide (SUH), three singed unwashed meat (SUM); three singed washed hide (SWH), three singed washed meat (SWM) samples were collected from each abattoir i.e. 18 samples per abattoir. Each single type of sample (singed or unsigned hide and meat) was collected from the same animal for quality assurance purposes. The unsigned samples were collected to serve as a basis for determining the deposition of PAHs on the samples after singeing with rubber tyre. Portions of each sample (100 g) were milled in the Chemistry Laboratory of Michael Okpara University of Agriculture Umudike (MOUAU) Umuahia, Abia State, wrapped with aluminum foil to prevent exposure to light and were preserved in a refrigerator (at $4{ }^{\circ} \mathrm{C}$ ) prior to analysis. They were sent to Technology Partner International, TPI, Port Harcourt, Rivers State for PAH analysis.

Gas Chromatography/flame Ionization Detector (GCFID) Analysis: The target analytes included sixteen (16) non-alkylated PAHs, achieved through isolation, identification and quantification of the 16 priority pollutants, which follows a standard procedure of ultrasonic extraction, sample clean up and analysis based on GC-FID capabilities. The PAHs contents in the sample were determined using USEPA 8270D test method and the quantification of the PAH analytes using an Agilent 6890N GC. PAH extraction employed USEPA 3550c test method (Sewage waste, SW-846 methods) with some modifications. This method involves the use of ultrasonic extractor with dichloromethane (DCM) as the eluting solvent. About $10 \mathrm{~g}$ of milled samples was transferred into a $20 \mathrm{ml}$ vial and $1.0 \mathrm{ml}$ of matrix spiking solution, methanolic potassium hydroxide, $\mathrm{KOH}(20 \mathrm{ml} 0.5 \mathrm{M}$ $\mathrm{KOH}$ in $100 \mathrm{ml}$ methanol) was added (Method 3500).

The extraction was done ultrasonically for $10-12$ min with output control knob set at 10 (full power), the mode switch on pulse (to acquire pulsing energy rather than continuous energy) and the percent-duty cycle knob set at $50 \%$. The resultant mixture was sent to centrifugation at $300 \mathrm{rpm}$ for $10 \mathrm{~min}$. The extract was decanted and put in a centrifuge bottle. The extraction process was repeated again using $100 \mathrm{ml}$ portion of clean solution maintaining the same rpm. The supernatant or extract obtained was dried (not to total dryness) by passing it through a dry column containing about $10 \mathrm{~g}$ of anhydrous sodium sulphate, $\mathrm{Na}_{2} \mathrm{SO}_{4}$. The extract obtained was concentrated by rotary evaporator to obtain oily extract, which was transferred into a test tube. The flask was rinsed with $1 \mathrm{ml}$ of dichloromethane (DCM) and added to the test tube and shaken vigorously. The mixture was taken through the centrifuge at $200 \mathrm{rpm}$ for $5 \mathrm{~min}$. The supernatant was transferred into a new tube and the centrifugation was repeated. Then the supernatants were combined and made up to $10 \mathrm{ml}$ with DCM. The supernatant was concentrated to the final concentration $(1 \mathrm{ml})$ using rotary evaporator for 10 $20 \mathrm{~min}$ followed by clean- up process.

The clean- up was done according to silica gel cleanup technique (USEPA Method 3630c), in line with the determinative method (method 8100/8310). The elution was performed by $1 \mathrm{~cm}$ moderately packed glass wool placed at the bottom of $10 \mathrm{~mm}$ ID x 250 $\mathrm{mm}$ long chromatographic column. Slurry of $10 \mathrm{~g}$ activated silica gel in $10 \mathrm{ml}$ dichloromethane (DCM) was prepared and placed into the chromatographic column (200 mesh size), which had been preconditioned (pre-wet) with hexane. $1 \mathrm{~g}$ of anhydrous Sodium sulphate, $\mathrm{Na}_{2} \mathrm{SO}_{4}$ was added on the top of the column (on top of silica gel in the column). The extract was eluted with $20 \mathrm{ml}$ of hexane for aliphatic fractions in the column, $20 \mathrm{ml}$ of DCM was added for PAHs elution and the eluent was concentrated to $1 \mathrm{ml}$ (final concentration). The final extract was transferred into a sample vial equipped with a Polytetrafluoroethylene (PTFE) lined screw-cap from where $1 \mu \mathrm{L}$ of the extract was injected into a preprogrammed HP 6890N GC-FID for PAHs analysis.

PAH Analysis: The analysis was carried out based on the American Standards for Testing and Material (ASTM) standards. The extract obtained from the ultrasonic extraction were quantified for PAH analytes using $30 \mathrm{~m} \times 0.25 \mathrm{um} \times 0.25 \mathrm{~mm}$ ID long chromatographic column calibrated with standard solution of 16 component priority PAH Certified Reference Material (CRM) purchased from Chemservices, West Chester, USA. The calibration standard included USEPA 8270 LCS mix (semivolatile compound mix ,Supelco, Inc, St. Louis, MO; lot number LB21442), which included the target analytes: Acenaphthene, acenaphthylene, anthracene, benzo[a]anthracene, benzo [a] pyrene, Benzo

[b] fluoranthene, benzo [g,h,i] perylene,

benzo[k]fluoranthene, chrysene,

dibenz[a,h]anthracene, dibenzofuran, fluoranthene

fluorene, indeno[1,2,3.c.d]pyrene, naphthalene, phenanthrene, pyrene, 1-methylnaphthalene. The prepared solution contained a concentration of $100 \mu \mathrm{g} / \mathrm{ml}$ of all the compounds mixed in a solution of 90:10 methylene chlorides: acetone. Each standard (Surrogate, 8270 LCS mix) was analyzed using an Agilent 6890N Gas Chromatography coupled with Flame Ionization Detector (Hewlett Packard, HP, Wilmington, DE, USA). 
The elution times for all the non-alkylated target analytes and the surrogate compounds (2fluorobiphenyl and 1-fluoronaphthalene) were confirmed through replicate analyses in which the elution time for each individual component remained consistent $( \pm 0.1 \mathrm{~min})$. As soon as the elution times were confirmed, the PAH identification was carried out based on comparison of the retention times of the obtained analytes with those from standard mixture of PAHs (standard supplied by instrument manufacturer). Quantification of the compounds was based on external calibration curve prepared from the standard solution of each of the PAHs and all the samples were analyzed by GC-FID under the instrument parameters.

Statistical Analysis: Statistical analysis was done using the SPSS (version 20.0) for Windows software package. Mean concentrations and standard deviations were calculated for each parameter. The results were also subjected to analysis of variance (ANOVA) and means were compared using Duncan Multiple Range Test. The means of the PAHs concentrations were compared with relevant standards and appropriate deductions were made.

\section{RESULTS AND DISCUSSION}

Table 1 shows the profile the 16 PAHs analyzed in samples collected from Aba. Mean naphthalene concentration was significantly higher $(\mathrm{P}<0.05)$ than the concentrations of other PAHs in the six singed samples (SUH, SUM, SWH and SWM). Acenaphthylene, 1,2-dibenzoanthracene, chrysene, benzo(b)fluoranthene and benzo(k)fluoranthene were not detected in any of the samples while phenanthrene, anthracene, fluroanthene, pyrene, 1,2,5,6-dibenzoanthracene and 1, 12-benzopyrene were undetected in the unsigned samples but were present in the hide and meat samples (with the exception of 1, 12-benzoperylene which was not detected in SUM and SWM samples) singed with rubber tyres. This shows that singeing cow samples with rubber tyres adds unwanted PAHs to the hide and meat samples. PAH concentrations in singed, unwashed hide samples (SUH) were significantly higher $(\mathrm{P}<0.05)$ than concentrations in singed unwashed meat (SUM), singed washed hide (SWH) and singed unwashed meat (SUM) samples. SWM samples also had PAH concentrations which were significantly lower $(\mathrm{P}<0.05)$ than those of SUM and SWH samples. This brings to the fore the fact that thorough washing of the singed samples reduces PAH concentrations in both hide and meat samples by as much as $85 \%$ in the case of 1,2,5,6Dibenzanthracene in SUH and SWH samples. Benzo(a) pyrene is a well-known carcinogen and was formerly used as a marker for PAHs. European Union (2014) maximum limits for benzo(a)pyrene in smoked meat and smoked products is $2 \mu \mathrm{g} / \mathrm{kg}$. Benzo(a)pyrene concentrations were lower than the EU limits in the consumer ready singed washed samples but was higher in the singed unwashed hide sample. However, the benzo(a)pyrene concentration of $1.90 \mu \mathrm{g} / \mathrm{kg}$ in SWH is considered high since it was close to the limit. Reinik et al., (2007) reported that home prepared meat products (processed with scrap motor tyres), especially those which were prepared using a disposable grill contained higher concentrations of $\mathrm{BaP}$ and $\mathrm{PAHs}$ compared to the commercial product. The mean concentrations of $\mathrm{BaP}$ in industrial and disposable grill meat were $0.17 \mu \mathrm{g} / \mathrm{kg}$ and $1.0 \mu \mathrm{g} / \mathrm{kg}$, respectively. The mean concentrations of the PAHs in samples from Umuahia are shown in Table 2.

Only naphthalene, flourene, benzo(a)pyrene and 1, 12- Benzoperylene were observed in unsinged samples (UH) while naphthalene, anthracene and benzo(a)pyrene were in unsigned meat (UM) samples. For the singed samples, all the PAHs were observed except acenaphthene (in SUM, SWH and SWM samples), acenapthylene (in all singed samples), phenanthrene (in all singed samples), pyrene (in all singed samples), 1,2-dibenzanthracene (in all singed samples), chrysene (in all singed samples), benzo(k)fluoranthene (in all singed samples), Indo(1,2,3.c.d)pyrene, 1,2,5,6Dibenzoanthracene in (in all singed samples) and 1, 12-benzoperylene (in SUM, SWH and SWM samples).

Table 1: Mean concentrations of PAHs in samples collected from Aba

\begin{tabular}{llllllll}
\hline PAHs Profile & Abbr. & \multicolumn{7}{c}{ Samples and PAH concentrations $(\mu \mathrm{g} / \mathrm{kg})$} \\
\cline { 3 - 8 } & & UH & UM & SUH & SUM & SWH & SWM \\
Naphthalene & NaP & $2.30 \pm 0.70$ & $0.20 \pm 0.00$ & $20.80 \pm 2.30$ & $8.70 \pm 2.40$ & $9.50 \pm 1.80$ & $3.70 \pm 1.85$ \\
Acenaphthene & ACT & $1.00 \pm 0.00$ & $0.60 \pm 0.00$ & $8.20 \pm 3.40$ & $5.00 \pm 1.35$ & $3.70 \pm 1.00$ & $0.30 \pm 0.00$ \\
Acenaphthylene & ANP & ND & ND & ND & ND & ND & ND \\
Fluorene & FLR & $2.00 \pm 0.90$ & ND & $7.20 \pm 1.90$ & $2.50 \pm 0.80$ & $3.20 \pm 1.10$ & $0.30 \pm 0.01$ \\
Phenanthrene & PHN & ND & ND & $4.40 \pm 0.80$ & $1.36 \pm 0.40$ & $1.90 \pm 0.75$ & $0.10 \pm 0.00$ \\
Anthracene & ANT & ND & ND & $2.00 \pm 0.20$ & ND & $0.90 \pm 0.00$ & ND \\
Fluroanthene & FA & ND & ND & $11.20 \pm 2.50$ & $5.50 \pm 1.60$ & $5.20 \pm 2.30$ & $1.30 \pm 0.05$ \\
Pyrene & PYR & ND & ND & $2.80 \pm 0.65$ & $1.00 \pm 0.70$ & $0.70 \pm 0.00$ & $0.80 \pm 0.00$ \\
1,2-Dibenzanthracene & DBA & ND & ND & ND & ND & ND & ND \\
Chrysene & CHR & ND & ND & ND & ND & ND & ND \\
Benzo(b)fluoranthene & BbFA & ND & ND & ND & ND & ND & ND \\
Benzo(k)fluoranthene & BkFA & ND & ND & ND & ND & ND & ND \\
Benzo(a)pyrene & BaP & $0.10 \pm 0.00$ & ND & $4.80 \pm 1.50$ & $1.20 \pm 0.35$ & $1.90 \pm 0.70$ & $0.70 \pm 0.01$ \\
indeno[1,2,3.c.d]pyrene & IP & $0.20 \pm 0.00$ & $0.1 \pm 0.00$ & $7.50 \pm 1.30$ & $3.30 \pm 1.40$ & $2.10 \pm 0.45$ & $2.10 \pm 0.85$ \\
1,2,5,6-Dibenzoanthracene & DBA & ND & ND & $2.70 \pm 0.95$ & $0.60 \pm 0.00$ & $0.40 \pm 0.00$ & $0.20 \pm 0.00$ \\
$1,12-$ Benzoperylene & BP & ND & ND & $0.80 \pm 0.00$ & ND & $0.50 \pm 0.00$ & ND \\
\hline
\end{tabular}


Abbr. = abbreviation, $\mathrm{UH}=$ unsinged hide sample, $\mathrm{UM}=$ unsinged meat sample, $\mathrm{SUH}=$ singed unwashed hide sample, $\mathrm{SUM}=$ singed unwashed meat sample, $\mathrm{SWH}=$ singed washed meat sample, $\mathrm{SWM}=$ singed washed meat sample, ND = not detected

Table 2: Mean concentrations of PAHs in samples collected from Umuahia

\begin{tabular}{|c|c|c|c|c|c|c|c|}
\hline \multirow[t]{2}{*}{ PAHs Profile } & \multirow[t]{2}{*}{ Abbr. } & \multicolumn{6}{|c|}{ Samples and PAH concentrations $(\mu \mathrm{g} / \mathrm{kg})$} \\
\hline & & $\mathrm{UH}$ & $\overline{\mathrm{UM}}$ & SUH & $\overline{\text { SUM }}$ & SWH & SWM \\
\hline Naphthalene & $\mathrm{NaP}$ & $0.80 \pm 0.00$ & $1.50 \pm 0.30$ & $10.20 \pm 1.80$ & $2.10 \pm 0.60$ & $3.20 \pm 0.90$ & $1.00 \pm 0.40$ \\
\hline Acenaphthene & ACT & ND & ND & $0.10 \pm 0.00$ & ND & ND & ND \\
\hline Acenaphthylene & ANP & ND & ND & ND & ND & ND & ND \\
\hline Fluorene & FLR & $1.20 \pm 0.00$ & ND & $6.30 \pm 1.50$ & $1.50 \pm 0.00$ & $1.80 \pm 0.30$ & $1.00 \pm 0.30$ \\
\hline Phenanthrene & PHN & ND & ND & ND & ND & ND & ND \\
\hline Anthracene & ANT & ND & $0.70 \pm 0.00$ & $2.10 \pm 0.30$ & $0.20 \pm 0.00$ & $0.50 \pm 0.00$ & ND \\
\hline Fluroanthene & FA & ND & ND & $8.20 \pm 2.00$ & $2.70 \pm 0.60$ & $2.33 \pm 0.80$ & $1.30 \pm 0.10$ \\
\hline Pyrene & PYR & ND & ND & ND & ND & ND & ND \\
\hline 1,2-Dibenzanthracene & DBA & ND & ND & ND & ND & ND & ND \\
\hline Chrysene & CHR & ND & ND & ND & ND & ND & ND \\
\hline Benzo(b)fluoranthene & $\mathrm{BbFA}$ & ND & ND & $8.60 \pm 3.00$ & $5.00 \pm 2.00$ & ND & $1.30 \pm 0.20$ \\
\hline Benzo(k)fluoranthene & BkFA & ND & ND & ND & ND & ND & ND \\
\hline Benzo(a)pyrene & $\mathrm{BaP}$ & $1.70 \pm 0.20$ & $1.20 \pm 0.00$ & $12.00 \pm 3.80$ & $5.70 \pm 1.30$ & $2.70 \pm 0.90$ & $2.10 \pm 0.80$ \\
\hline indeno $[1,2,3 . c . d]$ pyrene & IP & ND & ND & ND & ND & ND & ND \\
\hline 1,2,5,6-Dibenzoanthracene & DBA & ND & ND & ND & ND & ND & ND \\
\hline 1,12 - Benzoperylene & BP & $0.90 \pm 0.00$ & ND & $2.50 \pm 0.80$ & ND & ND & ND \\
\hline
\end{tabular}

Abbr. = abbreviation, $\mathrm{UH}=$ unsinged hide sample, $\mathrm{UM}=$ unsinged meat sample, $\mathrm{SUH}=$ singed unwashed hide sample, $\mathrm{SUM}=$ singed unwashed meat sample, $\mathrm{SWH}=$ singed washed meat sample, $\mathrm{SWM}=$ singed washed meat sample, $\mathrm{ND}=$ not detected

Mean concentrations of PAHs were significantly higher $(\mathrm{P}<0.05)$ in SUH samples compared to concentrations of similar PAHs in other types of samples. Thorough washing of the hides led to the reduction of PAH concentration in washed samples which is seen in lower concentrations observed in SWH and SWM samples compared to SUH and SUM samples. Mean Benzo(a)pyrene concentrations were higher in the consumer ready singed washed hide and meat samples (SWH and SWM) than the EU limit of $2 \mu \mathrm{g} / \mathrm{kg}$. In a study of barbecued cattle and goat, $\mathrm{BaP}$ concentration was found to be as high as $130 \mu \mathrm{g} / \mathrm{kg}$ whereas the average background values are usually in the range of $0.01-1.0 \mu \mathrm{g} / \mathrm{kg}$ in uncooked meat sample (FEHD, 2004). Kazerouni et al. (2001) concluded that the consumption of grilled or barbequed meat was the main factor contributing to $21 \%$ of daily intake of $\mathrm{BaP}$ in the United States. Farhadian et al. (2010) observed that beef products contained the maximum concentrations of $\mathrm{BaP}(12.5$ $\mu \mathrm{g} / \mathrm{kg}$ ) compared to other grilled meat products like grilled chicken. Chung et al. (2011) reported relatively high levels of PAHs (mean $10.2 \mu \mathrm{g} / \mathrm{kg}$ ) in charcoal-grilled pork samples but low levels (maximum $0.80 \mu \mathrm{g} / \mathrm{kg}$ ) in beef. Charcoal grilling also resulted in high levels of benzo(a)pyrene $(3.0 \mu \mathrm{g} / \mathrm{kg})$ in pork samples but relatively low levels (mean 0.15 $\mu \mathrm{g} / \mathrm{kg}$ ) in beef samples. Table 3 shows the profile the 16 PAHs analyzed in samples collected from Okigwe

Table 3: Mean concentrations of PAHs in samples collected from Okigwe

\begin{tabular}{|c|c|c|c|c|c|c|c|}
\hline \multirow[t]{2}{*}{ PAHs Profile } & \multirow[t]{2}{*}{ Abbr. } & \multicolumn{6}{|c|}{ Samples and PAH concentrations $(\mu \mathrm{g} / \mathrm{kg})$} \\
\hline & & UH & UM & SUH & SUM & SWH & SWM \\
\hline Naphthalene & $\mathrm{NaP}$ & $1.70 \pm 0.20$ & $2.10 \pm 0.90$ & $10.30 \pm 2.00$ & $4.80 \pm 1.40$ & $2.50 \pm$ & $3.10 \pm 1.20$ \\
\hline Acenaphthene & $\mathrm{ACT}$ & ND & ND & ND & ND & ND & ND \\
\hline Acenaphthylene & ANP & $0.12 \pm 0.00$ & $0.10 \pm 0.00$ & $3.20 \pm 1.10$ & $1.0 \pm 0.20$ & $1.50 \pm 0.40$ & $0.40 \pm 0.00$ \\
\hline Fluorene & FLR & ND & ND & $5.30 \pm 2.00$ & $1.40 \pm 0.30$ & $1.60 \pm 0.30$ & $0.70 \pm 0.00$ \\
\hline Phenanthrene & PHN & $0.20 \pm 0.00$ & ND & $8.10 \pm 1.70$ & $3.90 \pm 0.80$ & $2.60 \pm 0.90$ & $1.70 \pm 0.00$ \\
\hline Anthracene & ANT & ND & ND & $4.70 \pm 1.50$ & ND & ND & ND \\
\hline Fluroanthene & FA & ND & ND & $1.20 \pm 0.40$ & $0.20 \pm 0.00$ & ND & ND \\
\hline Pyrene & PYR & ND & ND & $0.50 \pm 0.00$ & ND & ND & ND \\
\hline 1,2-Dibenzanthracene & DBA & ND & ND & ND & ND & ND & ND \\
\hline Chrysene & CHR & ND & ND & ND & ND & ND & ND \\
\hline Benzo(b)fluoranthene & BbFA & ND & ND & ND & ND & ND & ND \\
\hline Benzo(k)fluoranthene & BkFA & ND & ND & ND & ND & ND & ND \\
\hline Benzo(a)pyrene & $\mathrm{BaP}$ & ND & ND & $3.30 \pm 1.40$ & ND & $0.90 \pm 0.00$ & ND \\
\hline indeno $[1,2,3 . c . d]$ pyrene & IP & $0.20 \pm 0.00$ & ND & $6.20 \pm 0.40$ & $1.70 \pm 0.10$ & $1.50 \pm 0.30$ & ND \\
\hline 1,2,5,6-Dibenzoanthracene & DBA & ND & ND & $2.10 \pm 0.50$ & $0.90 \pm 0.00$ & $0.60 \pm 0.00$ & $1.00 \pm 0.20$ \\
\hline 1, 12-Benzoperylene & $\mathrm{BP}$ & ND & ND & ND & ND & ND & ND \\
\hline
\end{tabular}

Abbr. = abbreviation, $\mathrm{UH}=$ unsinged hide sample, $\mathrm{UM}=$ unsinged meat sample, $\mathrm{SUH}=$ singed unwashed hide sample, $\mathrm{SUM}=$ singed unwashed meat sample, $\mathrm{SWH}=$ singed washed meat sample, $\mathrm{SWM}=$ singed washed meat sample, $\mathrm{ND}=$ not detected

Mean naphthalene concentration in SUH sample $(10.30 \pm 2.00 \mu \mathrm{g} / \mathrm{kg})$ was significantly higher $(\mathrm{P}<0.05)$ than concentrations in other samples. Acenaphthene, 1,2-dibenzanthracene, chrysene, benzo(b)fluoranthene, benzo(k)fluoranthene and 1, 12-benzoperylene were not detected in any sample from Okigwe. Other PAHs which were detected followed the profile of naphthalene and had significantly higher $(\mathrm{P}<0.05)$ mean concentrations in SUH samples than in others. Washing samples with water led to lower levels of PAHs in washed samples (SWH and SWM) compared to unwashed samples (SUH and SUM). However, mean 1,2,5,6dibenzoanthracene concentration in SWM sample was higher than mean concentrations in SUM and SWH samples. Benzo(a)pyrene was detected in the hide ( $\mathrm{SUH}$ and $\mathrm{SWH}$ ) samples. Mean BaP concentrations in the 
singed washed samples (SWH and SWM) were lower than the EU concentration limits. The profile of mean PAHs concentrations in samples from Mbaise is shown in Table 4.

Table 4: Mean concentrations of PAHs in samples collected from Mbaise

\begin{tabular}{|c|c|c|c|c|c|c|c|}
\hline \multirow[t]{2}{*}{ PAHs Profile } & \multirow[t]{2}{*}{ Abbr. } & \multicolumn{6}{|c|}{ Samples and PAH concentrations $(\mu \mathrm{g} / \mathrm{kg})$} \\
\hline & & $\overline{\mathrm{UH}}$ & UM & SUH & SUM & SWH & SWM \\
\hline Naphthalene & $\mathrm{NaP}$ & $0.80 \pm 0.00$ & $1.10 \pm 0.30$ & $8.20 \pm 1.60$ & $3.10 \pm 0.60$ & $2.80 \pm 0.70$ & $2.10 \pm 0.90$ \\
\hline Acenaphthene & ACT & ND & ND & $4.00 \pm 0.80$ & $1.70 \pm 0.30$ & $0.90 \pm 0.10$ & $0.30 \pm 0.00$ \\
\hline Acenaphthylene & ANP & $0.80 \pm 0.00$ & ND & $2.10 \pm 0.60$ & ND & $0.70 \pm 0.00$ & ND \\
\hline Fluorene & FLR & ND & ND & $4.50 \pm 1.70$ & $0.30 \pm 0.00$ & $1.80 \pm 0.90$ & ND \\
\hline Phenanthrene & PHN & ND & ND & $7.20 \pm 2.30$ & $3.70 \pm 1.00$ & $2.90 \pm 0.80$ & ND \\
\hline Anthracene & ANT & $0.40 \pm 0.00$ & ND & $5.00 \pm 1.20$ & $2.00 \pm 0.40$ & $2.50 \pm 0.70$ & $1.00 \pm 0.20$ \\
\hline Fluroanthene & FA & $0.10 \pm 0.00$ & ND & $1.80 \pm 0.10$ & $0.70 \pm 0.00$ & ND & ND \\
\hline Pyrene & PYR & ND & ND & $2.60 \pm 0.90$ & ND & ND & ND \\
\hline 1,2-Dibenzanthracene & DBA & ND & ND & $1.40 \pm 0.30$ & ND & ND & ND \\
\hline Chrysene & CHR & ND & ND & ND & ND & ND & ND \\
\hline Benzo(b)fluoranthene & BbFA & ND & ND & ND & ND & ND & ND \\
\hline Benzo(k)fluoranthene & BkFA & ND & ND & ND & ND & ND & ND \\
\hline Benzo(a)pyrene & $\mathrm{BaP}$ & ND & ND & $1.20 \pm 0.00$ & ND & $0.30 \pm 0.00$ & ND \\
\hline indeno $[1,2,3 . c . d]$ pyrene & IP & $0.10 \pm 0.00$ & ND & $3.90 \pm 1.00$ & $2.30 \pm 0.80$ & $1.50 \pm 0.70$ & ND \\
\hline 1,2,5,6-Dibenzoanthracene & DBA & ND & ND & $2.70 \pm 0.40$ & $0.70 \pm 0.10$ & ND & ND \\
\hline 1,12-Benzoperylene & BP & ND & ND & ND & ND & ND & ND \\
\hline
\end{tabular}
unwashed meat sample, $\mathrm{SWH}=$ singed washed meat sample, $\mathrm{SWM}=$ singed washed meat sample, ND = not detected

Only naphthalene, acenaphthylene, anthracene, fluroanthene and indeno[1,2,3.c.d]pyrene were detected in unsinged hide (UH) samples while all PAHs except naphthalene were not detected in unsinged meat (UM) samples. In the singed unwashed hide (SUH) samples, mean naphthalene and phenanthrene concentrations were similar $(\mathrm{P}>0.05)$ but were significantly higher $(\mathrm{P}<0.05)$ than the mean concentrations of other PAHs. Mean phenanthrene concentrations were higher in singed unwashed meat (SUM) and singed washed hide $(\mathrm{SWH})$ with values of $3.70 \pm 1.00$ and $2.90 \pm 0.80$ $\mu \mathrm{g} / \mathrm{kg}$, respectively. Mean naphthalene concentration was significantly higher $(\mathrm{P}<0.05)$ in singed washed meat (SWM) samples compared to the mean concentrations of other PAHs. Chrysene, benzo(b)fluoranthene, benzo(k)fluoranthene and 1 , 12- Benzoperylene were not detected in any of the singed or unsinged samples. Mean benzo(a)pyrene concentrations were lower than the EU benchmark of $2 \mu \mathrm{g} / \mathrm{kg}$. Values for BaP concentration were much lower than value of $130 \mu \mathrm{g} / \mathrm{kg}$ obtained by Mottier et al. (2000) in barbecued cattle and goat. Average background values for $\mathrm{BaP}$ concentration were usually in the range of $0.01-1.0 \mu \mathrm{g} / \mathrm{kg}$ in uncooked meat sample (FEHD, 2004).

Conclusion and Recommendations: The PAHs contents of cattle hide and meat samples processed with flame produced by scrap car tyre in abattoirs located in Umuahia, Aba, Okigwe and Mbaise, South-Eastern Nigeria, were evaluated with Gas chromatography. The European Union (2014) limits for benzo(a)pyrene in smoked meat and smoked products is $2 \mu \mathrm{g} / \mathrm{kg}$. The results revealed that PAHs concentrations in consumer ready singed washed samples from Aba were lower than both the EU limit in the consumer ready singed washed samples. For samples collected from Umuahia, mean benzo(a)pyrene concentrations were higher in the consumer ready singed washed hide and meat samples (SWH and SWM) compared to the EU limit of $2 \mu \mathrm{g} / \mathrm{kg}$. Mean BaP concentrations in the singed washed samples (SWH and SWM) from Okigwe were lower than the EU limits. In samples from Mbaise, mean benzo(a)pyrene concentrations were also lower than the EU limit. The results indicate that ingesting cow hide and meat singed with tyre will put consumers at the risk of health hazards from PAH contamination and it is recommended that the government at all levels should enact and enforce laws banning the use of scrap rubber tyres for processing food.

\section{REFERENCES}

Adam I; Okyere D; Teye M (2013). Assessment of Heavy Metals Residues in Hides of Goats singed with tyres and the Effect of boiling on the heavy metal Concentrations in the Hides. J. Vet. Adv. 3(5):165-169

Alonge DO (1988). Carcinogenic Polycyclic Aromatic Hydrocarbons Determined in Nigerian Smoke-dried Meat. J. Sci. Food Agric. 43:167 172

Chung SY; Yettella Ramesh R; Kim JS; Kwon K; Kim MC; Min-David B (2011). Effects of grilling and roasting on the levels of polycyclic aromatic hydrocarbons in beef and pork. Food Chem. 129(4): 1420-1426

EU (2014). European Commission Regulation (EU) No 1327/2014 of 12 December 2014 amending Regulation (EC) No 1881/2006 as regards maximum levels of polycyclic aromatic 
hydrocarbons (PAHs) in traditionally smoked meat and meat products and traditionally smoked fish and fishery products

Farhadian A; Jinap S; Hanifah HN; Zaidul IS (2011). Effects of meat preheating and wrapping on the levels of polycyclic aromatic hydrocarbons in charcoal-grilled meat. Food Chem. 124(1): 141146

Garcia-Falcon MS; Simal-Gandara J (2005). Polycyclic Aromatic Hydrocarbons in smoke from Different fire source and the Transfer during Traditional smoking. Food Add. Contam. 22:1-8

Hamparsun H; Hilal C (2010).Investigation of Polycyclic Aromatic Hydrocarbons in foods. Asian J. Chem. 8: 5777 - 5807

Kazerouni N; Sinha R; Greenberg-Hsu CH; Rothman $N$ (2001).Analysis of 200 food items for Benzo[a]pyrene and Estimation of its intake in epidemiologic study. Food Chem. Toxicol. 39(5): $423-436$
Mottier P; Parisod V; Turesky RJ (2000). Quantitative Determination of Polycyclic Aromatic Hydrocarbons in Barbecued Meat Sausage by Gas Chromatography coupled to Mass Spectrometry. J. Agric. Food Chem. 48:1160 - 1166

Obiri-Danso K; Hogarh JN; Antwi-Agyei P (2008). Assessment of Contamination of singed hides from cattle and goat by heavy metals. Afr. J. Env. Sci. Technol. 2(8): $217-221$

Okiel W; Ogunlesi M; Alabi F; Osiughwu B; Sojinrin A (2009). Determination of toxic metal concentrations in flame treated meat products. Afr. J. Biochem. Res. 3(10): 332 - 339.

Reinik M; Tamme T; Roasto M; Juhkam K; Tenno T; Kiis A (2007). Food Add. Contam. 24: 429.

FEHD (2004). Risk Assessment Studies: PAHs in Barbecued Meat Report No. 14. Food and environmental Hygiene Department, The Government of the Hong-Kong Special Administration Region. 